\title{
Sodium channel biophysics, late sodium current and genetic arrhythmic syndromes
}

\author{
Karan R. Chadda ${ }^{1,2}$ - Kamalan Jeevaratnam ${ }^{1,3}$ - Ming Lei ${ }^{4}$. \\ Christopher L.-H. Huang ${ }^{2,5}$
}

Received: 21 January 2017 / Accepted: 14 February 2017 /Published online: 6 March 2017

(C) The Author(s) 2017. This article is published with open access at Springerlink.com

\begin{abstract}
Arrhythmias arise from breakdown of orderly action potential (AP) activation, propagation and recovery driven by interactive opening and closing of successive voltagegated ion channels, in which one or more $\mathrm{Na}^{+}$current components play critical parts. Early peak, $\mathrm{Na}^{+}$currents $\left(I_{\mathrm{Na}}\right)$ reflecting channel activation drive the AP upstroke central to cellular activation and its propagation. Sustained late $\mathrm{Na}^{+}$currents $\left(I_{\mathrm{Na}-\mathrm{L}}\right)$ include contributions from a component with a delayed inactivation timecourse influencing AP duration (APD) and refractoriness, potentially causing pro-arrhythmic phenotypes. The magnitude of $I_{\mathrm{Na}-\mathrm{L}} \mathrm{can}$ be analysed through overlaps or otherwise in the overall voltage dependences of the steady-state properties and kinetics of activation and inactivation of the $\mathrm{Na}^{+}$conductance. This was useful in analysing repetitive firing associated with paramyotonia congenita in skeletal muscle. Similarly, genetic cardiac $\mathrm{Na}^{+}$channel abnormalities increasing $I_{\mathrm{Na}-\mathrm{L}}$ are implicated in triggering phenomena of automaticity, early and delayed afterdepolarisations and arrhythmic substrate. This review illustrates a wide range of situations that may accentuate $I_{\mathrm{Na}-\mathrm{L}}$. These include (1)
\end{abstract}

Christopher L.-H. Huang

clh11@cam.ac.uk

1 Faculty of Health and Medical Sciences, University of Surrey, VSM Building, Guildford GU2 7AL, UK

2 Physiological Laboratory, University of Cambridge, Downing Street, Cambridge CB2 3EG, UK

3 School of Medicine, Perdana University-Royal College of Surgeons Ireland, 43400 Serdang, Selangor Darul Ehsan, Malaysia

4 Department of Pharmacology, University of Oxford, Oxford OX1 3QT, UK

5 Department of Biochemistry, University of Cambridge, Hopkins Building, Cambridge CB2 1QW, UK overlaps between steady-state activation and inactivation increasing window current, (2) kinetic deficiencies in $\mathrm{Na}^{+}$channel inactivation leading to bursting phenomena associated with repetitive channel openings and (3) non-equilibrium gating processes causing channel re-opening due to more rapid recoveries from inactivation. All these biophysical possibilities were identified in a selection of abnormal human SCN5A genotypes. The latter presented as a broad range of clinical arrhythmic phenotypes, for which effective therapeutic intervention would require specific identification and targeting of the diverse electrophysiological abnormalities underlying their increased $I_{\mathrm{Na}-\mathrm{L}}$.

Keywords Sodium channel activation · Sodium channel inactivation - Late sodium current $\cdot$ Paramyotonia congenita Cardiac arrhythmic syndromes

$\begin{array}{ll}\text { Abbreviations } \\ A & \text { Arrhenius constant } \\ \text { AF } & \text { Atrial fibrillation } \\ \text { AP } & \text { Action potential } \\ \text { APD } & \text { Action potential duration } \\ \text { ATX-II } & \text { Anemonia sulcata toxin } \\ \text { AVN } & \text { Atrioventricular node } \\ \text { BrS } & \text { Brugada syndrome } \\ \text { DAD } & \text { Delayed afterdepolarisation } \\ \text { EAD } & \text { Early afterdepolarisation } \\ \text { ECG } & \text { Electrocardiographic } \\ F & \text { Faraday's constant } \\ g_{\mathrm{Na}} & \text { Sodium conductance } \\ g_{\mathrm{Na}}{ }^{*} & \text { Maximum value of sodium conductance } \\ I_{\mathrm{Ca}} & \text { Calcium current } \\ \mathrm{IFM} & \text { Isoleucine-phenylalanine-methionine } \\ I_{\mathrm{K} 1} & \text { Inward rectifying } \mathrm{K}^{+} \text {current }\end{array}$


$I_{\mathrm{Kr}} \quad$ Rapid delayed rectifier $\mathrm{K}^{+}$current

$I_{\mathrm{Ks}} \quad$ Slowly activating delayed rectifier $\mathrm{K}^{+}$current

$I_{\mathrm{Na}} \quad$ Sodium current

$I_{\text {Na-L }} \quad$ Late sodium current

$I_{\text {to }} \quad$ Transient outward $\mathrm{K}^{+}$current

$k \quad$ Boltzmann constant

$k_{\text {act }} \quad$ Slope factor for activation

$k_{\text {inact }} \quad$ Slope factor for inactivation

$k_{\mathrm{mn}} \quad$ Voltage-dependent rate constants

LQTS3 Long QT syndrome type 3

MEPPC Multifocal ectopic Purkinje-related premature contractions

$R \quad$ Gas constant

SAN Sino-atrial node

SCD Sudden cardiac death

SIDS Sudden infant death syndrome

$T \quad$ Temperature

TdP Torsades de pointes

$V \quad$ Membrane potential

$V_{\text {act }} \quad$ Voltage at half-maximum activation

$V_{\text {inact }} \quad$ Voltage at half-maximum inactivation

VT Ventricular tachycardia

$z \quad$ Valency

$\alpha_{h} \quad$ Time constant for transition into inactivation

$\beta_{h} \quad$ Time constant for recovery from inactivation

\section{Introduction}

Arrhythmias follow disruption of the normal interacting succession of ion channel activation and inactivation that produces the transmembrane currents underlying the propagated action potential (AP) $[10,23,80]$. In skeletal muscle, these manifest as a range of syndromes associated with repetitive action potential firing associated with a number of ion channel abnormalities. Where involving the heart, ventricular arrhythmia potentially results in sudden cardiac death (SCD), which accounts for $\sim 4$ to 5 million deaths per year worldwide [17]. Cardiac ischaemia accounts for most cases of arrhythmia [9], but $\sim 10-20 \%$ of arrhythmic deaths may result from ion channelopathy [40]. These could affect ion channels carrying $\mathrm{Na}^{+}$, $I_{\mathrm{Na}}$, and $\mathrm{Ca}^{2+}$ depolarizing currents, $I_{\mathrm{Ca}}$, and a number of, $I_{\mathrm{to}}$, $I_{\mathrm{Kr}}, I_{\mathrm{Ks}}$ and $I_{\mathrm{K} 1}, \mathrm{~K}^{+}$channels contributing repolarizing current $[57,70]$. The depolarisation-activated $I_{\mathrm{Ca}}$ induces $\mathrm{Ca}^{2+}$ release from intracellular sarcoplasmic reticular $\mathrm{Ca}^{2+}$ stores which triggers mechanical activity. The detailed AP timecourse in different cardiac regions or animal species is determined by their corresponding patterns of ion channel expression [71]. Once generated, local circuit currents driven by the inward flux of $\mathrm{Na}^{+}$propagate APs to hitherto quiescent myocardial regions through gap junctions between successive cells. The result is a wave of membrane depolarisation followed by refractoriness [39].
The $\mathrm{Na}^{+}$channel is central to this excitation process in view of its strategic role in initiation of the cardiac AP. The $\mathrm{Na}^{+}$ current, $I_{\mathrm{Na}}$, may comprise a mixture of currents with different kinetics. These might arise from modulations in the principal $\mathrm{Na}_{\mathrm{v}}$ species or distinct channel subpopulations [67, 68]. Functional alterations in the biophysical properties of the $\mathrm{Na}^{+}$channel thus lead to a range of arrhythmic conditions. An important group of these is the result of sustained inward $\mathrm{Na}^{+}$current. The repetitive firing observed in skeletal muscle fibres in patients with paramyotonia congenita arises from an incomplete voltage-dependent $\mathrm{Na}^{+}$channel inactivation thus leaving some channels in a conductive state [45]. This results from mutations in the skeletal muscle $\mathrm{Na}_{\mathrm{v}} 1.4$ channel $[22,44$, 69] that produce positive shifts in the half maximal voltage of its steady-state inactivation function $\left(V_{\text {inact }}\right)$. Alternatively, negative shifts in the voltage dependence of $\mathrm{Na}^{+}$channel activation $\left(V_{\text {act }}\right)$ permit channel activation with smaller depolarisations. Either situation potentially results in sustained inward current that follows excitation that can cause recurrent channel re-activation [12, 28, 29].

In cardiac muscle, sustained inward $\mathrm{Na}^{+}$currents also known as late $\mathrm{Na}^{+}$currents $\left(I_{\mathrm{Na}-\mathrm{L}}\right)$ occur under physiological conditions during the cardiac AP. These currents nevertheless have conductance, mean open time and selectivity properties identical to the remaining $\mathrm{Na}_{\mathrm{v}} 1.5$ current $[25,37]$. It remains possible to consider both early $\mathrm{Na}^{+}$currents and potentially arrhythmogenic $I_{\mathrm{Na}-\mathrm{L}}$ in terms of the overall activation and inactivation characteristics that they produce in cardiac myocytes. A comparison with clinical findings will demonstrate that cardiac muscle shows a wider range of possible variations in such characteristics than the straightforward shifts in steady-state activation and inactivation reported so far in skeletal muscle. These findings have implications for therapeutic intervention.

\section{$\mathrm{Na}^{+}$channel activation and inactivation}

The cardiac $\mathrm{Na}^{+}$channel multi-unit protein comprises principal $\mathrm{Na}_{\mathrm{v}} 1.5, \alpha$ - and associated auxiliary $\beta$-subunits. The $\alpha$ subunit consists of four homologous domains (I-IV) each containing six transmembrane segments (S1-S6) [8], and it suffices to mediate ion selectivity, and the voltage-gated activation and inactivation properties of the channel [62]. Voltagegated $\mathrm{Na}_{\mathrm{v}} 1.5$ activation depends on transitions in the $\mathrm{S} 4$ segment whose positively charged amino acids at every third position likely subserve a voltage-sensing function [13]. Membrane depolarisation moves the S4 segment relative to other channel segments so that the voltage-sensing domain, formed by the $\mathrm{S} 1-\mathrm{S} 4$ block, rotates. This permits $\mathrm{Na}^{+}$influx through the pore-forming component made up of the S5 and S6 segments and the re-entrant $\mathrm{P}$ loop $[21,50]$. This early $I_{\mathrm{Na}}$ drives the rapid AP upstroke resulting in further channel activation. Hodgkin and Huxley (1952) had first described such 
activation in terms of three $m$ particles undergoing a voltagedependent, first-order transition from an inactive to active state, giving channel openings of higher-order kinetics [32]. The maximum attainable $\mathrm{Na}^{+}$current would depend upon the number of available channels, and be compromised in situations of $\mathrm{Na}_{\mathrm{v}} 1.5$ insufficiency, as in Brugada syndrome $(\mathrm{BrS})$ [42].

$\mathrm{Na}_{\mathrm{v}} 1.5$ inactivation terminates the inward $I_{\mathrm{Na}}$ permitting membrane repolarisation also driven by other, outward, ionic currents. $\mathrm{Na}_{\mathrm{v}} 1.5$ inactivation involves two, fast and slow, kinetic components. Fast inactivation occurs within milliseconds and results from the cytoplasmic III-IV linker occluding the pore [38]. This may involve an isoleucine-phenylalaninemethionine (IFM) motif, which is a hydrophobic triplet in the III-IV linker that may act as a 'latch' keeping the fast inactivation gate shut [38]. Docking sites for this inactivation gate likely include the S6 segment in domain IV and the S4-5 loops in domains III and IV [8]. Hodgkin and Huxley correspondingly described a parallel first-order, voltage-dependent $h$-inactivation process resulting in refractoriness with prolonged depolarisation and recovery from such refractoriness with repolarisation. Slow inactivation, subsequently reported in NaF-perfused Loligo axons [14, 63], may include structurally distinct components [83], likely involving conformational changes of the pore component of the $\alpha$-subunit [81].

These processes have been organised in a reaction scheme in which a channel transitions through several closed $\left(C_{0}\right.$ to $C_{3}$ ) resting states, then an open $(O)$ state, with voltagedependent rate constants $k_{\mathrm{mn}}$ intervening between any given pair of states $m$ and $n$. The channel then transitions through inactivated $\left(I_{1}\right.$ and $\left.I_{2}\right)$ states, followed by recovery from inactivation, similarly governed by voltage-dependent rate constants $\alpha_{h}$ and $\beta_{h}$ (Fig. 1). The latter suggests resting, activated and inactivated states of the channel in which the channel is closed during resting and inactivated states, with separate processes mediating activation and inactivation. Channel opening with depolarisation is dependent not only upon the extent of activation but also upon the extent to which channels have transitioned into an inactivated state. These openings increase the membrane $\mathrm{Na}^{+}$conductance, $g_{\mathrm{Na}}$, in turn permitting a peak

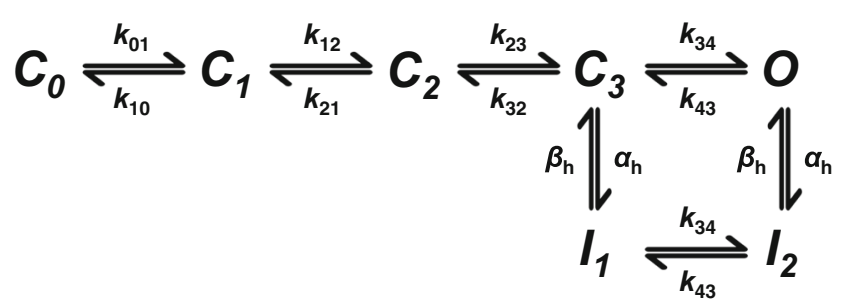

Fig. 1 Sequence of $\mathrm{Na}^{+}$channel states. State diagram representing transitions between closed $(C)$, open $(O)$ and inactivated $(I)$ states of the $\mathrm{Na}^{+}$channel incorporating ionic and gating current data, showing the voltage-dependent rate constants $\left(k_{\mathrm{mn}}, \alpha_{h}\right.$ and $\left.\beta_{h}\right)$ which determine the kinetics of transitions between states [81]
$I_{\mathrm{Na}}$ or $I_{\mathrm{Na}-\mathrm{L}}$ to take place down its net electrochemical driving force $\left(V-E_{\mathrm{Na}}\right)$, contributing to the in vivo waveform of the cardiac AP (Fig. 2a). An early peak $I_{\mathrm{Na}}$ related to the activation process of the channel drives the upstroke of the AP and rapidly inactivates within a few milliseconds. The $\mathrm{Na}^{+}$channel component underlying $I_{\mathrm{Na}-\mathrm{L}}$ shows a diminished or slowed inactivation and a more negative $(20 \mathrm{mV})$ voltage dependence in its activation properties than the remaining $I_{\mathrm{Na}}$ [68]. Early modelling predicted an $I_{\mathrm{Na}-\mathrm{L}}$ of magnitude $\sim 1-2 \%$ of peak $I_{\mathrm{Na}}$ $[48,58]$. Increases in $I_{\mathrm{Na}-\mathrm{L}}$ thus influence AP duration and refractoriness. Currents arising from additional background $I_{\mathrm{bNa}}$ attributed to $\mathrm{Na}^{+}-\mathrm{K}^{+}$-ATPase and $\mathrm{Na}^{+}-\mathrm{Ca}^{2+}$ exchange-mediated leak currents are distinct from the voltage-dependent $\mathrm{Na}^{+}$channel processes analysed here $[7,15,31,58]$.

\section{Graphical representation of $\mathrm{Na}^{+}$channel activation and inactivation}

Figure 3 illustrates graphical representations of the consequences of these activation and inactivation processes and their possible interaction, which predicts the resulting $I_{\mathrm{Na}}$. First, the steady-state activation curve illustrates the potential increase in $\mathrm{Na}^{+}$conductance and therefore of $I_{\mathrm{Na}}$ as a function of the membrane potential $V$. Each individual $I_{\mathrm{Na}}$ component would reflect a conductance contribution $g_{\mathrm{Na}}$ described by a Boltzmann distribution between two, open and closed, states whose energies that vary linearly with $V$. This would predict a sigmoid relationship between $g_{\mathrm{Na}}$ and $V$. In the equation,

$g_{\mathrm{Na}}=g_{\mathrm{Na}} * /\left\{1+\exp \left[-\left(V-V_{\mathrm{act}}\right) / k_{\mathrm{act}}\right]\right\}$,

term $g_{\mathrm{Na}}{ }^{*}$ is the maximum value of $g_{\mathrm{Na}}$ and $V_{\text {act }}$ is the voltage at its half-maximum value. The term $k_{\text {act }}$ is the slope factor for activation, which characterises the voltage sensitivity of the component channel in terms of the valency, $z$, of the charge transfer involved in its transitions between the open and closed states, through the equation $k_{\text {act }}=R T /(z F)$, where $R=$ gas constant, $T=$ temperature and $F=$ Faraday's constant. Either increasing the value of $\mathrm{z}$ or reducing the value of $k_{\text {act }}$ will increase the steepness of the activation-voltage relationship.

Second, steady-state inactivation curves normalised to the interval $[0,1]$ give an indication of the fraction of activatable channels mediating each $\mathrm{Na}^{+}$conductance component, $h$, as limited by the degree of inactivation, each with its own inactivation slope factor $k_{\text {inact }}$,

$h=1 /\left\{1+\exp \left[-\left(V-V_{\text {inact }}\right) / k_{\text {inact }}\right]\right\}$.

Third, in addition to their steady-state properties, the activation and inactivation processes show distinct kinetics. Inactivation kinetics is typically slower than activation 


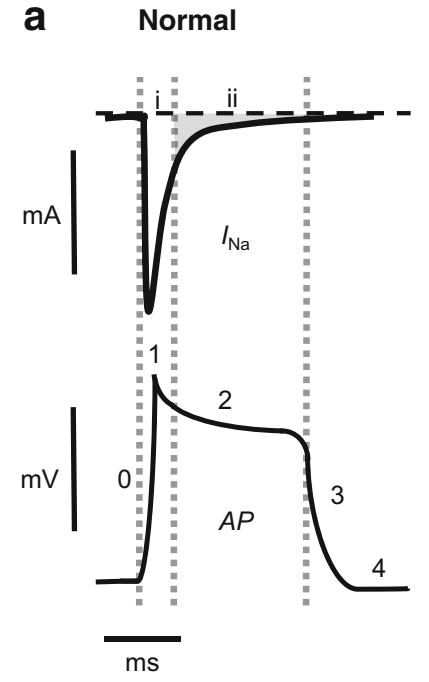

b Increased $I_{\mathrm{Na}-\mathrm{L}}$
Fig. 2 Relationships between peak and late $\mathrm{Na}^{+}$currents and cardiac action potential timecourse. Comparisons of situations expected under conditions of normal (a) and prolonged action potential (AP) recovery timecourse (b). This illustrates the increase in amplitude and duration of

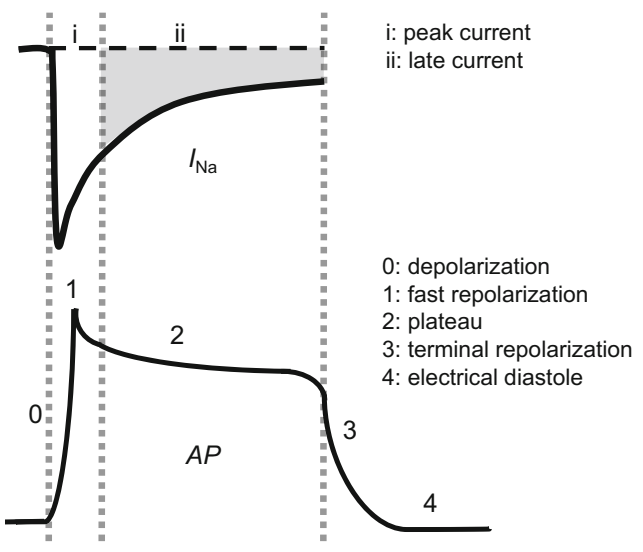

late $\mathrm{Na}^{+}$current $\left(I_{\mathrm{Na}-\mathrm{L}}\right)$ (top panels) in relationship to the timecourse of the successive phases $(0-4)$ of the cardiac AP (bottom panels) under normal (a) and conditions associated with increased $I_{\mathrm{Na}-\mathrm{L}}(\mathbf{b})$. Changes in $I_{\mathrm{Na}-\mathrm{L}}$ magnitude are not drawn to scale kinetics and extends over timescales comparable to the recovery phase of the AP. A family of inactivation curves rather than a single inactivation curve could be used to represent the time evolution of the inactivation process as might occur following imposition of a given voltage step. For any given component, the simplest two-state model might assume activatable and inactivated states of energies $E_{1}(V)$ and $E_{2}(V)$, respectively, linearly dependent on the voltage $V$ through a coefficient dependent on their effective position in the membrane field. It could then incorporate forward, $\alpha$, and backward, $\beta$, rate constants determined by the energy of the barrier $E^{*}(V)$ given by $\alpha(V)=A \exp \left\{\left[E_{1}(V)-E^{*}(V)\right] / k T\right\}$ and $\beta(V)=A \exp \left\{\left[E_{2}(V)-\right.\right.$ $\left.\left.E^{*}(V)\right] / k T\right\}$, where $k$ in this instance represents the Boltzmann constant and $A$ the Arrhenius constant [1].

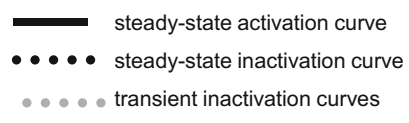

a

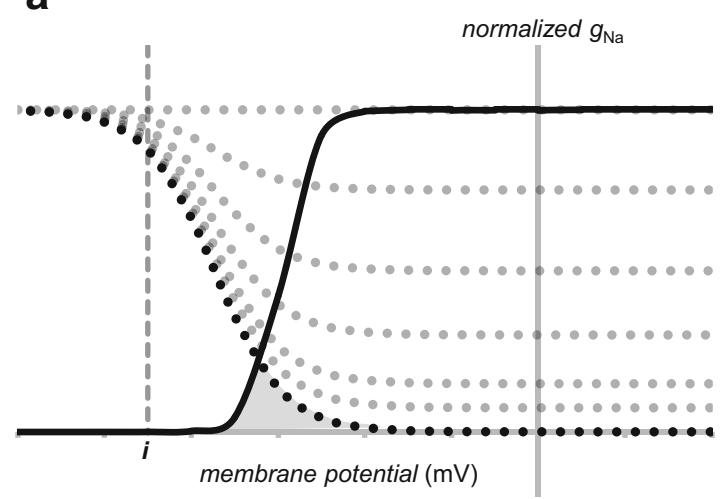

Fig. 3 Curves illustrating the voltage dependence for $\mathrm{Na}^{+}$channel activation and inactivation under steady-state and transient conditions. a Normalised steady-state activation and inactivation curves (after [51]) as well as a family of transient inactivation curves expected at successively greater intervals following the onset of a large voltage step (a) from the resting potential $(i) \mathrm{Na}^{+}$conductance $\left(g_{\mathrm{Na}}\right)$ is normalised to peak $g_{\mathrm{Na}}$ obtained in response to a depolarizing voltage step of sufficient magnitude to elicit maximum peak $\mathrm{Na}^{+}$conductance. b Superimposed upon these activation curves is an illustration of the trajectory of $\mathrm{Na}^{+}$

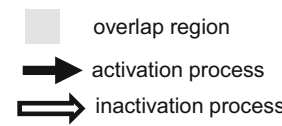

b

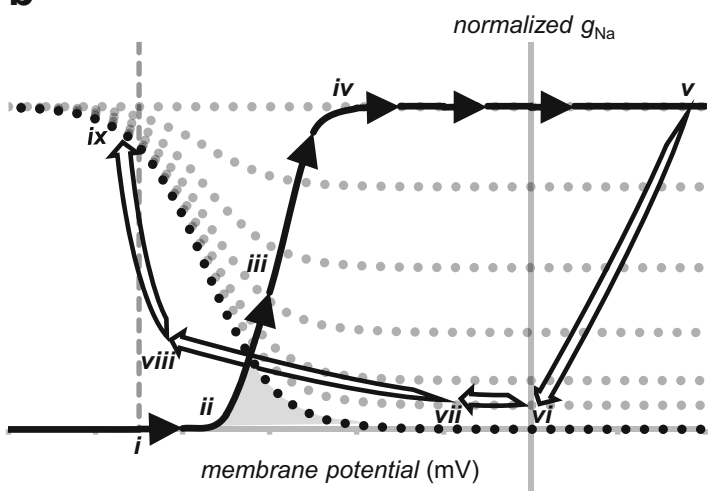

current activation (continuous line, arrowed) from the resting potential (i) through voltages along the increasing (ii)-(iv) and plateau regions (iv) and $(v)$ of the activation curve. This is followed by the trajectory of $\mathrm{Na}^{+}$current inactivation from the action potential peak $(v)$ through phase 1 rapid repolarisation $((v)-(v i))$, the phase 2 plateau $((v \mathrm{i})-(v i i))$, phase 3 repolarisation $((v i i)-(v i i i))$ and restoration of electrical diastole $((v i i)-(i x))$, over which the $\mathrm{Na}^{+}$channel recovers from refractoriness. The overlap between the activation and inactivation curves is shaded grey to illustrate conditions under which a physiological window current would be expected 
The relationship between $\mathrm{Na}^{+}$channel activation and inactivation curves and the late $\mathrm{Na}^{+}$current, $I_{\mathrm{Na}-\mathrm{L}}$

The relative contributions of activation and inactivation properties can be assessed from plots of their respective overall dependencies upon voltage. These are shown in functions illustrated using established experimental values in Fig. 3a [51]. An imposed voltage step would produce a rapid activation of $g_{\mathrm{Na}}$, whose value would fall close to the corresponding ordinate of the activation curve. Thus, there will initially be little evidence of the slower inactivation process, but this will subsequently cause $g_{\mathrm{Na}}$ to decline. This time evolution of inactivation is represented by the successive dotted transient inactivation curves that progressively approach the steady-state inactivation curve, which would predict full inactivation at depolarised voltages. Alternatively, a persistent conductance would result from an incomplete inactivation either at times when the relevant decay is incomplete or in the event of an incomplete steady-state inactivation at the voltage in question. Thus, the effective $g_{\mathrm{Na}}$ at any given time following a particular voltage step is effectively the ordinate in the activation multiplied by corresponding ordinate in the inactivation function.

Figure $3 \mathrm{~b}$ reconstructs both the $g_{\mathrm{Na}}$ activation (full arrows) and inactivation variables (open arrows) through the timecourse of the cardiac AP. The charging of an initially quiescent membrane at the resting potential (i) by local circuit currents through the passive cable formed by intervening cardiac myocytes from previously excited membrane regions produces an activation locus ((i)-(ii)) to the foot of the activation-voltage relationship. The resulting $\mathrm{Na}^{+}$channel opening initiates a regenerative cycle of depolarisation and further channel opening producing the steep rise of $g_{\mathrm{Na}}$ along the activation curve from ((ii)-(iii)) to maximum channel activation along ((iv)-(v)), thereby completing phase 0 of the cardiac AP. The inactivation locus is then followed through phase 1 fast early repolarisation ((v)-(vi)), during which there is a rapid $\mathrm{Na}^{+}$channel inactivation. This is succeeded by the phase 2 plateau ((vi)-(vii)), during which an incomplete development of inactivation leaves a finite $I_{\mathrm{Na}-\mathrm{L}}$. Locus ((vii)-(viii)) traces phase 3 terminal repolarisation and a return to electrophysiological diastole at the resting potential ((viii)-(ix)). Recovery from inactivation is favoured at membrane potentials near to the resting potential and this then permits re-excitation.

\section{Importance of late $\mathrm{Na}^{+}$current, $I_{\mathrm{Na}-\mathrm{L}}$}

Figure 2a illustrates a presence of $I_{\mathrm{Na}-\mathrm{L}}$ during the AP plateau phase, whereas Fig. 2b illustrates circumstances of increased $I_{\mathrm{Na}-\mathrm{L}}$. In addition to extending the plateau duration before AP recovery, an increased $I_{\mathrm{Na}-\mathrm{L}}$ can lead to the development of various triggers and substrates for arrhythmogenesis. First, it can cause diastolic depolarisation phenomena, which trigger inappropriate APs in the sino-atrial node (SAN) and the potentially pacemaking atrioventricular node (AVN) and HisPurkinje cells. This can result in an abnormal automaticity reduced by inhibiting such $I_{\mathrm{Na}-\mathrm{L}}[23,76]$. Second, enhanced $I_{\mathrm{Na}-\mathrm{L}}$ can predispose to afterdepolarisations during or immediately following an AP [87]. Of these, early afterdepolarisations (EADs) occur during phase 2 or 3 of a prolonged AP [5, 23]. This then causes a regenerative L-type $\mathrm{Ca}^{2+}$ channel re-activation, whilst the membrane remains depolarised during a prolonged AP plateau phase. EADs have been observed both in genetic conditions such as long QT syndrome (LQTS) and acquired conditions such as cardiac failure [36]. Delayed afterdepolarisations (DADs) follow full repolarisation in cells with $\mathrm{Ca}^{2+}$ overload. These in turn predispose to depolarizing, transient inward currents. Although smaller than the peak $I_{\mathrm{Na}}$, $I_{\mathrm{Na}-\mathrm{L}}$ has a $50-100$-fold longer duration and thereby can increase cellular $\mathrm{Na}^{+}$loading, in turn reducing the gradient for $\mathrm{Ca}^{2+}$ efflux through sodium-calcium exchange current [58]. DADs may underlie arrhythmias seen in some heart failure patients, patients with digitalis toxicity and patients with catecholaminergic polymorphic ventricular tachycardia [5].

Third, the presence of $I_{\mathrm{Na}-\mathrm{L}}$ also bears upon re-entrant processes re-exciting recovered regions, thus furnishing arrhythmic substrate perpetuating the initial arrhythmic event [3]. $I_{\mathrm{Na}-\mathrm{L}}$ upregulation by Anemonia sulcata toxin (ATX-II) increased dispersion of repolarisation and refractoriness. This could lead to the torsades de pointes associated with LQTS [4]. Finally, $I_{\mathrm{Na}-\mathrm{L}}$ also increases the slope of the AP duration (APD) restitution curve relating AP duration to the diastolic interval intervening between AP recovery and generation of the subsequent AP during regular stimulation at successively higher frequencies $[59,78]$. A pathological $I_{\mathrm{Na}-\mathrm{L}}$ upregulation therefore promotes arrhythmic triggers and substrates through a variety of pathways, summarised in Fig. 4.

\section{$I_{\mathrm{Na}-\mathrm{L}}$ and altered $\mathrm{g}_{\mathrm{Na}}$ activation}

Increased $I_{\mathrm{Na}-\mathrm{L}}$ thus potentially constitutes a final common pathway explaining a wide range of pro-arrhythmic phenomena. However, a wide range of alterations in either or both of the biophysical properties of $g_{\mathrm{Na}}$ activation and inactivation (Fig. 5a) provide potential causative mechanisms for increased $I_{\mathrm{Na}-\mathrm{L}}$. These range from alterations in maximum $g_{\mathrm{Na}}$ despite an otherwise unaltered activation-voltage plot, as could occur following an increased surface membrane $\mathrm{Na}^{+}$channel expression (Fig. 5b). This situation would contrast with the consequences of some Brugada syndrome cases, which contain a $\mathrm{Na}_{\mathrm{v}} 1.5$ haploinsufficiency [51].

In the remaining cases, changes in either the steady-state or kinetic properties of activation and/or inactivation alters the interrelationship between these curves. This determines the 
Fig. 4 Simplified scheme illustrating mechanisms by which increased late sodium current can promote arrhythmogenesis

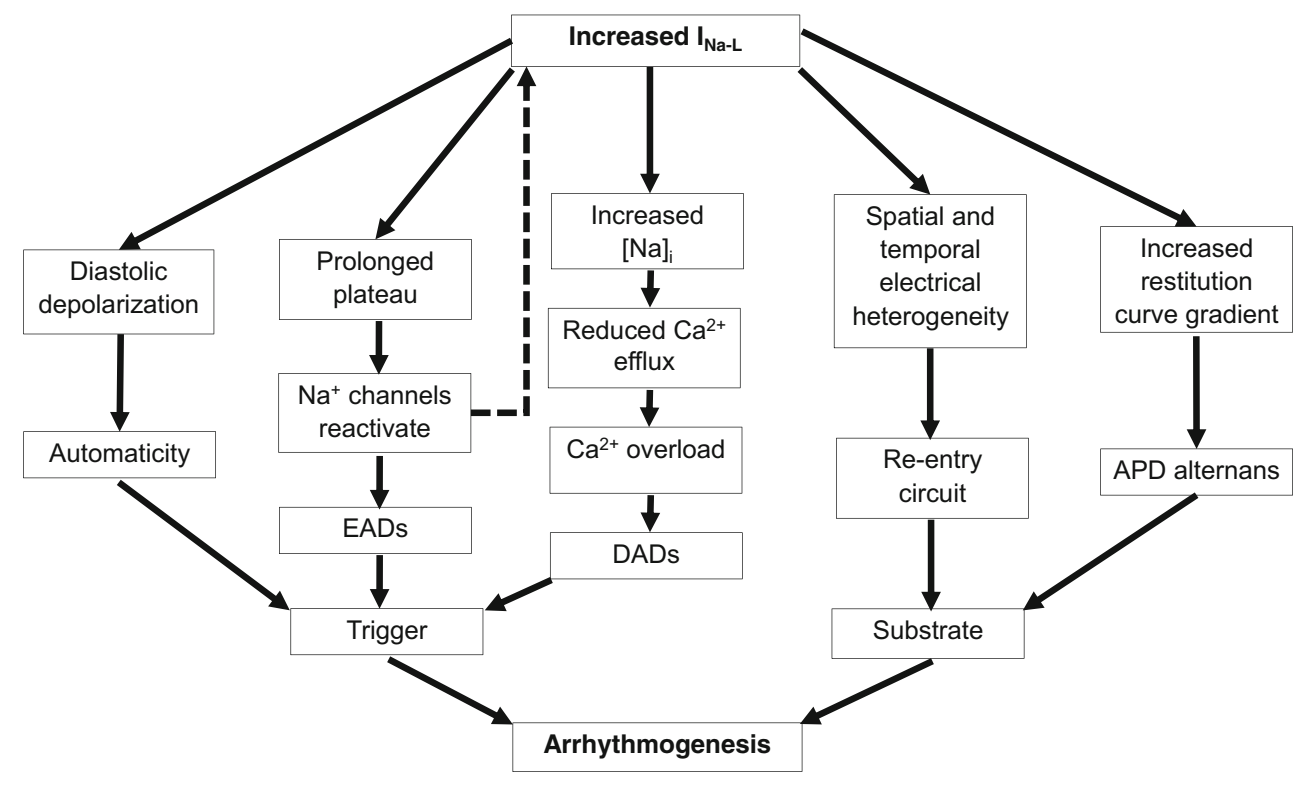

size of $I_{\mathrm{Na}-\mathrm{L}}$ whether in the form of a prolonged opening of $\mathrm{Na}^{+}$channels or a re-opening of previously inactivated channels [58]. In situations in which there are overlap regions in the steady-state activation and inactivation functions, an experimental situation involving the imposition of voltage clamp steps would demonstrate a persistent steady-state equilibrium, window current $[48,54]$. Similar overlaps could occur prior to achievement of a steady state. These would particularly arise from the kinetics of either activation or inactivation that would remain amenable to the graphical analysis adopted here.

Nevertheless, the relatively rapid kinetics of $\mathrm{Na}^{+}$channel activation over timescales substantially preceding recovery processes related to $I_{\mathrm{Na}-\mathrm{L}}$ permit its approximation by its steady-state activation curve properties. A number of activation curve variants could then potentially influence the existence or magnitude of $I_{\mathrm{Na}-\mathrm{L}}$. Of these, negative shifts in the

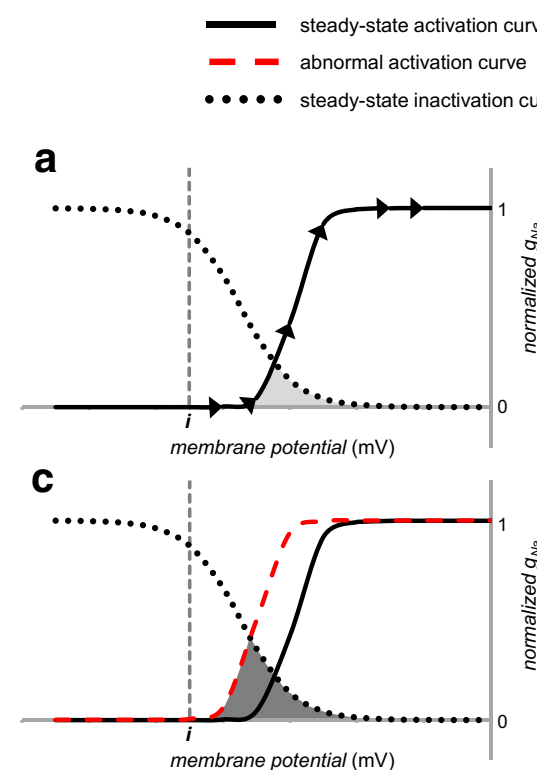

Fig. 5 Changes in the activation curve that would increase a depolarizing $I_{\mathrm{Na}}($ a). The normal activation curve and the activation trajectory following a depolarizing voltage step sufficient to cause maximum activation. This is compared with the steady-state inactivation curve. b Illustration of the consequences of an increase in maximum sodium conductance $\left(g_{\max }\right)$ without a change in its voltage sensitivity $\left(k_{\text {act }}\right)$. An increase in maximum activation takes place with relatively little change in the slope or the position of the curve along the horizontal axis. This would

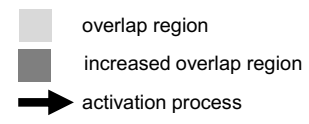

b

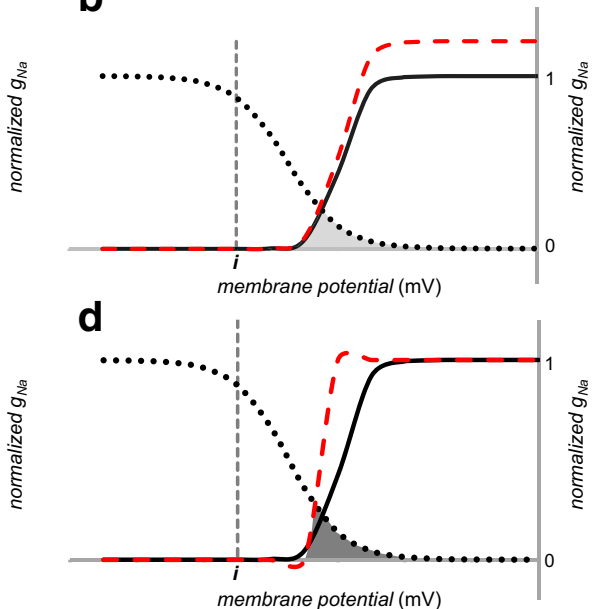

simply increase the peak sodium conductance. $\mathbf{c}$ Shift of the activation curve along the negative direction decreasing $V_{\text {act }}$, without altering its voltage sensitivity, $k_{\text {act }}$. This increases the overlap between the activation and inactivation curves. This abnormality increases $I_{\mathrm{Na}-\mathrm{L}}$ by increasing the window current. d Increases in the voltage sensitivity, corresponding to a decrease in $k_{\text {act }}$. This increases the overlap between the activation and inactivation curves and similarly increases $I_{\mathrm{Na}-\mathrm{L}}$ by increasing window current 
voltage dependence of activation quantified by negative changes in $V_{\text {act }}$ have been reported with genetic modification in either the $\mathrm{Na}_{\mathrm{v}} 1.5 \alpha$ - or $\beta$-subunits [27]. Alternatively, this negative change could occur in situations shifting the electric field seen by the voltage sensor for activation with reductions in external or increases in internal $\mathrm{Ca}^{2+}$ or $\mathrm{Mg}^{2+}$ concentration (Fig. 5c) $[52,73,75]$. These would shift the foot of the activation voltage curve closer to the threshold voltage and increase the likelihood of re-activation phenomena. In addition, an increased steepness in the activation curve (Fig. 5d) quantified by a decrease in $k_{\text {act }}$ and therefore an increase in the effective valency $z$ could arise in mutations affecting the charge on the voltage sensor controlling $\mathrm{Na}^{+}$channel gating.

\section{$I_{\mathrm{Na}-\mathrm{L}}$ and altered $\mathrm{g}_{\mathrm{Na}}$ inactivation}

Figure 6a illustrates both steady state and a family of curves (dotted lines) representing the kinetics of inactivation following a depolarizing voltage step, which explores the development of inactivation independently of its recovery. Both positive shifts, with increased $V_{\text {inact }}$ (Fig. 6b) or a decreased steepness with increased $k_{\text {inact }}$, of steady-state inactivation (Fig. 6c), could increase overlap between steady-state activation and
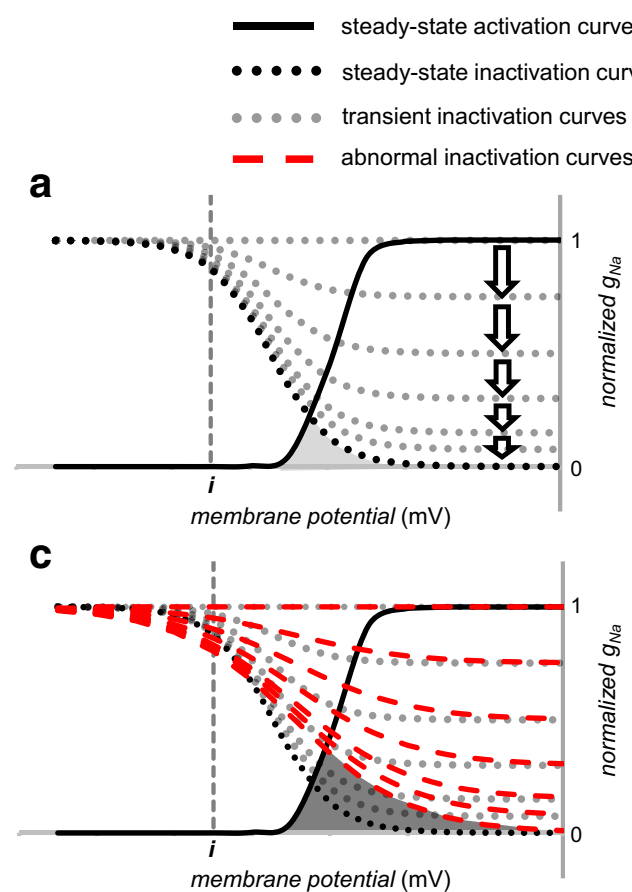

Fig. 6 Changes in the inactivation curve that would increase a depolarizing $I_{\mathrm{Na}}$. a Family of normal inactivation curves obtained at different intervals (arrows) following imposition of a positive depolarizing voltage step producing an initial $\mathrm{Na}^{+}$conductance activation along the activation curve. The arrows proceed vertically downward representing the transition to full steady-state inactivation as the membrane potential is clamped at a positive voltage. The length of the arrow denotes the rapidity of the process of inactivation is. b Positive shift of the inactivation curve along the voltage axis increasing $V_{\text {inact }}$ without altering its voltage sensitivity inactivation, accentuating $I_{\mathrm{Na}-\mathrm{L}}$ through an increased window current. In addition, alterations in inactivation kinetics could take place incidental to such shifts in steady-state inactivation or in a presence of otherwise normal steady-state properties. A slowing of the kinetics even in the absence of any steady-state abnormality (Fig. 6d) could result in a further mechanism of increasing $I_{\mathrm{Na}-\mathrm{L}}$ manifested in bursting phenomena. Bursting reflects a transient kinetic failure of $\mathrm{Na}^{+}$channel inactivation. The resulting gating mode is associated with a small proportion of the channels alternating between the last closed available state and open state (Fig. 1), and these frequent openings could give rise to $I_{\mathrm{Na}-\mathrm{L}}[18,79]$.

Finally, voltage steps restoring the resting membrane potential drive $\mathrm{Na}^{+}$channel recovery from inactivation over a refractory period (Fig. 7a). As in the case of inactivation, recovery kinetics can similarly follow altered (Fig. 7b) or take place in the presence of normal steady-state voltage dependencies of inactivation (Fig. 7c). This can increase $I_{\mathrm{Na}-\mathrm{L}}$ by a non-equilibrium gating process. The latter could cause channel re-opening due to a decreased recovery time from inactivation during the terminal repolarisation phase of the AP. This re-opening could take place beyond the overlap region between steady-state activation and inactivation curves.
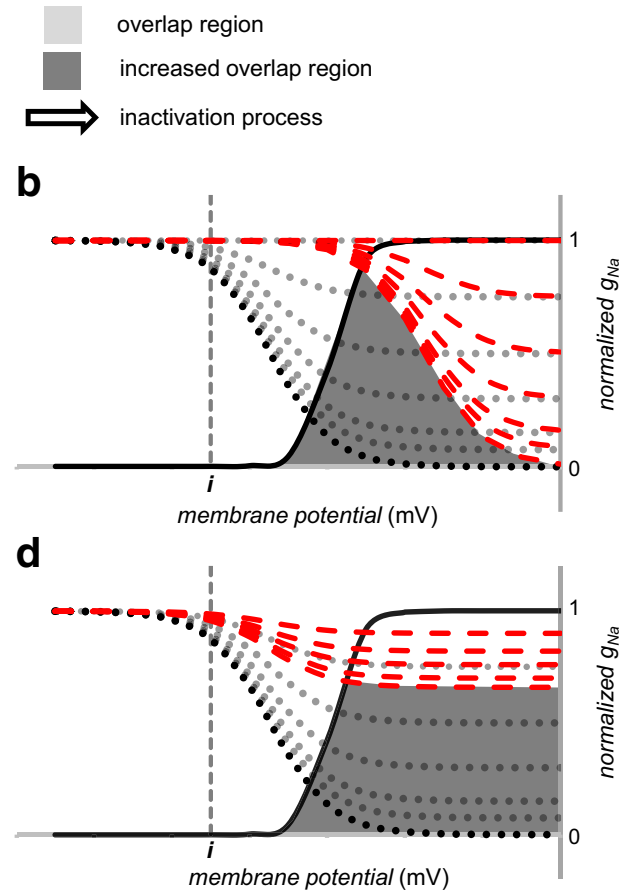

$k_{\text {inact }}$. This increases the overlap between activation and inactivation curves. This therefore increases $I_{\mathrm{Na}-\mathrm{L}}$ by increasing window current. c Increase in $k_{\text {inact }}$ decreasing the steepness of the inactivation curve. This also increases the overlap between the activation and inactivation curves, again increasing $I_{\mathrm{Na}-\mathrm{L}}$ by increasing window current. d Slowing of inactivation kinetics. At any given time, the transient inactivation curves then assume higher values than shown by the normal transient inactivation curves. As a result, at any given time, fewer $\mathrm{Na}^{+}$channels are inactivated, giving a higher sustained $I_{\mathrm{Na}-\mathrm{L}}$ potentially producing bursting behaviour 

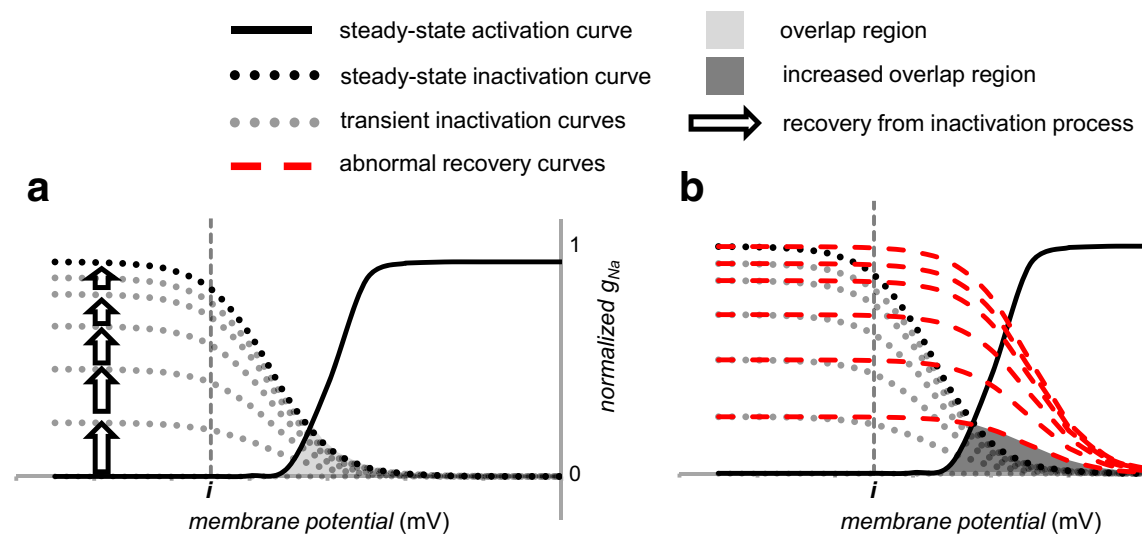

b

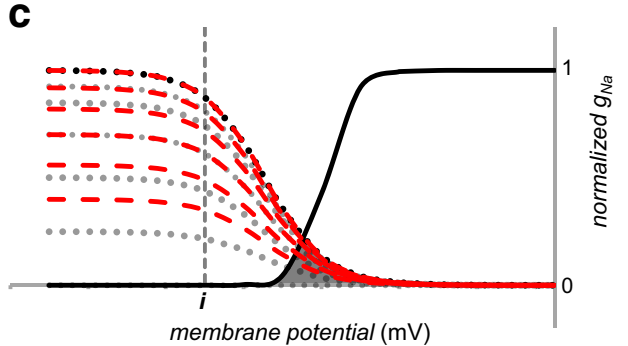

Fig. 7 Changes in the recovery from inactivation following the repolarizing phase ending a voltage step. The membrane potential is returned to a negative voltage near the resting potential. a The normal recovery from inactivation processes represented by upward pointing arrows proceed through a succession of transient inactivation curves

Thus, rapid recovery of a small subpopulation of the channels from inactivation permits their immediate re-activation [19]. Even following full restoration of the resting membrane at the end of the step, the examples in Fig. 7b, c may show similarly altered recovery kinetics. Such altered kinetics might reflect shifted steady-state inactivation curves, which would corespondingly shift rate constants involving inactivation or recovery from inactivation along the voltage axis. They could also result from alterations in the rate constants themselves. Either would alter rates of recovery from inactivation at a given voltage.

\section{$I_{\mathrm{Na}-\mathrm{L}}$ and clinical genetic arrhythmic conditions}

The previous sections thus suggest a hypothesis invoking a convergence of a range of $\mathrm{Na}^{+}$channel activation and inactivation abnormalities, all of which produce $I_{\mathrm{Na}-\mathrm{L}}$. Table 1 summarises a selection of experimental studies using expression systems of a range of inherited clinical mutations in human $S C N 5 A$, all of which have been associated with increased $I_{\mathrm{Na}}$ $\mathrm{L}$. It confirms that each mutation results in characteristics illustrating one or more of all the biophysical examples discussed above as illustrated by Figs. 5, 6 and 7. Conversely, the mutations in the table cover all these biophysical cases when taken together. Thus, an enhanced $I_{\mathrm{Na}-\mathrm{L}}$ can result from a large variety of abnormalities in $\mathrm{Na}^{+}$channel gating. approaching the steady-state inactivation curve at full recovery. The length of the arrow denotes the rapidity of the process. b Positive shift in the voltage dependence of recovery from inactivation increases the overlap between activation and inactivation. $\mathbf{c}$ Faster kinetics for the recovery from inactivation also increases this overlap. Both situations increase $I_{\mathrm{Na}-\mathrm{L}}$

In particular, Table 1 illustrates the above points in detail for long QT syndrome type 3 (LQTS3) using the relatively large number of examples from which selections can be made for analysis [33, 49, 55, 61, 65, 72, 85]. LQTS3 is one of a range of genetic (LQTS1-LQTS13) long QT syndromes characterised by prolonged QT intervals, reflecting increased ventricular APD and additional aberrant $T$-wave ECG signatures. They are all associated with a predisposition to normally self-terminating episodic polymorphic ventricular tachycardia (VT), torsades de pointes (TdP), with the potential to degenerate into ventricular fibrillation and/or SCD [2]. LQTS3 patients commonly exhibit bradycardia, and they show a greater risk of arrhythmia at lower heart rates, such as during rest and sleep [64]. The most common mechanism of LQTS3 pathophysiology is the disruption of the fast inactivation kinetics of the channel, enhancing $I_{\mathrm{Na}-\mathrm{L}}[30]$. However, the list of mutations in Table 1 suggests that each hypothetical alteration in activation and inactivation properties proposed above is associated with a particular case of LQTS3. The one exception concerns situations resulting in an increased steepness of the activation-voltage relationship and a consequent decrease in $k_{\text {act }}$. Nevertheless, the latter phenotype was represented in the particular, R225P and R814W, mutations. These are associated with complex arrhythmias combined with dilated cardiomyopathy. They showed an increased voltage sensitivity of the $\mathrm{Na}^{+}$channel. This took the form of a decrease in $k_{\text {act }}$ without any change in the inactivation curve [53]. 
Table 1 Biophysical characterisation of a selection of SCN5A mutations related to an increased $I_{\mathrm{Na}-\mathrm{L}}$ and clinical arrhythmic syndromes

\begin{tabular}{|c|c|c|c|c|c|c|c|c|}
\hline Mutation & $\begin{array}{l}\text { Increased } \\
\text { maximum } \\
g_{\mathrm{Na}}\end{array}$ & $\begin{array}{l}\text { Negatively } \\
\text { shifted } V_{\text {act }}\end{array}$ & $\begin{array}{l}\text { Decreased } \\
k_{\text {act }}\end{array}$ & $\begin{array}{l}\text { Positively } \\
\text { shifted } \\
V_{\text {inact }}\end{array}$ & $\begin{array}{l}\text { Increased } \\
k_{\text {inact }}\end{array}$ & $\begin{array}{l}\text { Slowed } \\
\text { inactivation } \\
\text { kinetics }\end{array}$ & $\begin{array}{l}\text { Accelerated } \\
\text { recovery } \\
\text { from } \\
\text { inactivation }\end{array}$ & Reference \\
\hline \multicolumn{9}{|c|}{ Long QT syndrome } \\
\hline p.R1644H & - & - & - & - & - & - & + & [49] \\
\hline p.H1849R & + & - & - & + & - & + & - & {$[55]$} \\
\hline R1626P & - & - & - & - & + & - & - & {$[65]$} \\
\hline P1332L & - & + & - & - & - & - & - & {$[65]$} \\
\hline M1652R & - & - & - & + & - & - & + & {$[65]$} \\
\hline S216L & + & + & - & - & - & - & - & {$[61]$} \\
\hline $\mathrm{R} 568 \mathrm{H}$ & + & - & - & + & - & - & - & {$[61]$} \\
\hline A572D & + & - & - & - & - & + & + & {$[61]$} \\
\hline V411M & - & + & - & - & - & - & - & {$[33]$} \\
\hline L409P/R558 & - & - & - & + & - & - & + & {$[85]$} \\
\hline P2006A & - & - & - & + & - & - & + & {$[72]$} \\
\hline \multicolumn{9}{|c|}{ Complex arrhythmia and dilated cardiomyopathy } \\
\hline $\mathrm{R} 225 \mathrm{P}$ & + & + & + & - & + & - & - & {$[53]$} \\
\hline R814W & - & + & + & - & - & - & - & {$[53]$} \\
\hline \multicolumn{9}{|c|}{ Sudden infant death syndrome } \\
\hline S1333Y & + & + & - & + & - & - & + & {$[34]$} \\
\hline \multicolumn{9}{|c|}{ Multifocal ectopic Purkinje-related premature contractions } \\
\hline p.R222Q & - & + & - & - & - & - & - & [43] \\
\hline \multicolumn{9}{|c|}{ Atrial fibrillation } \\
\hline p.H1849R & + & - & - & + & - & + & - & {$[55]$} \\
\hline K1493R & - & - & - & + & - & + & - & {$[46]$} \\
\hline \multicolumn{9}{|c|}{ Exercise-induced polymorphic arrhythmia } \\
\hline p.I141V & - & + & - & - & - & - & - & {$[77]$} \\
\hline
\end{tabular}

Conversely, a given $I_{\mathrm{Na}-\mathrm{L}}$ phenotype could be associated with a wide range of clinical manifestations in different patients. In addition to LQTS3, these include sudden infant death syndrome (SIDS), multifocal ectopic Purkinje-related premature contractions (MEPPC) and atrial fibrillation (AF). SIDS is a significant cause of infant mortality, and arrhythmias are an important cause of SIDS, with inherited LQTS making up 9.5\% of SIDS cases [6]. The S1333Y mutation in Table 1 associated with SIDS involves the domain III S4-S5 linker near the proposed docking site of regions implicated in channel inactivation. The mutant channel showed enhanced window and persistent inward currents, producing a LQTS3-like phenotype [34]. This mutation led to changes in both activation and inactivation processes that taken together would tend to increase $I_{\mathrm{Na}-\mathrm{L}}$. Thus, the S1333Y mutation resulted in an increased maximum $g_{\mathrm{Na}}$, a negatively shifted $V_{\text {act }}$ but a positively shifted $V_{\text {inact }}$. There was also a more rapid recovery from inactivation. However, there does exist a A1330P mutation that has similar ionic channel effects and also causes SIDS, yet does not produce enhanced $I_{\mathrm{Na}-\mathrm{L}}$ [34].

The autosomal dominant MEPPC syndrome is associated with an arrhythmia characterised by premature ventricular contractions that originate from ectopic foci along the fascicular-Purkinje system. This results in non-sustained VT and, depending on its severity, SCD [47]. A consistently observed window current may increase the excitability of the fascicular-Purkinje system [47]. Table 1 exemplifies one particular R222Q mutation, which clearly co-segregated with the MEPPC phenotype. This was uniformly present in three unrelated families, and dilated cardiomyopathy appeared as a secondary consequence. The triggered APs and premature ventricular contractions were attributed to altered voltage dependencies of $\mathrm{Na}_{\mathrm{v}} 1.5$ activation. They were absent at higher pacing frequencies, consistent with their disappearance during exercise [43]. Accordingly, as shown in Table 1, this MEPPC mutation resulted in a negatively shifted $V_{\text {act }}$.

$\mathrm{AF}$ is an abnormal heart rhythm manifesting as rapid, irregular beating and palpitations; dyspnoea; dizziness; and chest pain [41, 55]. The gain-of-function K1493R mutation associated with $\mathrm{AF}$ showed a positively shifted $V_{\text {inact }}$ that would increase the window current and reduce the excitation threshold and a slowed kinetics for inactivation [46]. However, mutations in genes other than $S C N 5 A$ have also been associated with AF, including SCN1OA and SCN1B. 
$S C N 10 A$ encodes the voltage-gated $\mathrm{Na}_{\mathrm{v}} 1.8$ known to be highly expressed in intracardiac neurons [84]. Its role is not fully understood but mutations in it are associated with disease phenotypes. Thus, the A1073 variant increases risks of AF consistent with functional studies, demonstrating increased peak $I_{\mathrm{Na}}$, increased $I_{\mathrm{Na}-\mathrm{L}}$ and prolonged fast inactivation [35]. Although peak $\mathrm{Na}_{\mathrm{v}} 1.8$ current is much smaller than peak $\mathrm{Na}_{\mathrm{v}} 1.5$ current, $I_{\mathrm{Na}-\mathrm{L}}$ arising from $\mathrm{Na}_{\mathrm{v}} 1.8$ is $20-50$ times higher than $I_{\mathrm{Na}-\mathrm{L}}$ arising from $\mathrm{Na}_{\mathrm{v}} 1.5$. Therefore, $\mathrm{Na}_{\mathrm{v}} 1.8$-mediated $I_{\mathrm{Na}-\mathrm{L}}$ could strongly influence APD [35]. Finally, a given $I_{\mathrm{Na}-\mathrm{L}}$ phenotype could be associated with more than one clinical manifestation. Thus, a negatively shifted $V_{\text {act }}$ arising from three different mutations, P1332L, p.R222Q and p.I141V, gave LQTS3, MEPPC and exercise-induced polymorphic arrhythmia, respectively $[43,65,77]$.

\section{$I_{\mathrm{Na}-\mathrm{L}}$ as a pharmacological target}

Increased $I_{\mathrm{Na}-\mathrm{L}}$ thus potentially triggers and provides substrate for arrhythmia under diverse circumstances. The analysis above would indicate that potential therapeutic candidates should target $I_{\mathrm{Na}-\mathrm{L}}$ through their action on the steady-state voltage dependence of $\mathrm{Na}^{+}$channel activation and/or inactivation and their kinetic properties. This would require such action to take directions and extents appropriate to minimizing $I_{\mathrm{Na}-\mathrm{L}}$ in the particular condition concerned. Such an action could be further enhanced if the applied agent selectively acted upon $I_{\mathrm{Na}-\mathrm{L}}$ as opposed to peak $I_{\mathrm{Na}}$.

This strategy is exemplified by recent explorations directed at paramyotonia congenita in skeletal muscle. For example, the anticonvulsant lamotrigine negatively shifted the inactivation $V_{1 / 2}$, modifying inactivation kinetics and decreasing $I_{\mathrm{Na}}$, in a HEK293 expression system expressing $\mathrm{Na}_{\mathrm{v}} 1.4$ [56]. Rufinamide positively shifted the voltage dependence of $I_{\mathrm{Na}}$ activation in human $\mathrm{Na}_{\mathrm{v}} 1.1$ transiently expressed in Xenopus oocytes [24]. Both lamotrigine and rufinamide at concentrations appropriate for achieving clinical anticonvulsant activity reduced myotonia in isolated human and rat skeletal muscle [74]. This could provide a model for selective therapeutic modifications of activation and inactivation in the cardiac $\mathrm{Na}_{\mathrm{v}} 1.5$ channel. These could be targeted at patients with particular specific genetic mutations if their underlying electrophysiological abnormalities could be characterised in order to predict their response to these drugs. The latter in turn could prompt clinical trials to assess the efficacy of the resulting $I_{\mathrm{Na}-}$ ${ }_{\mathrm{L}}$ inhibitors on the arrhythmic variants concerned.

Studies investigating the precise effects of $I_{\mathrm{Na}-\mathrm{L}}$ inhibitors on the biophysical properties of the $\mathrm{Na}^{+}$channel could lead to therapy targeted at cardiac arrhythmias associated with increased $I_{\mathrm{Na}-\mathrm{L}}$. LQTS patients who responded well to mexiletine carried mutations resulting in a negative shift in $V_{\text {act }}$, whereas patients whose QT intervals were not modified in response to mexiletine did not have a negative shift in $V_{\text {act }}$
[65]. This has implications in that it may be necessary to target the specific biophysical alteration in $\mathrm{Na}^{+}$channel function to effectively inhibit the pro-arrhythmic effects of $I_{\mathrm{Na}-\mathrm{L}}$. This would require further investigations of its biophysical actions on mutant $\mathrm{Na}_{\mathrm{v}} 1.5$. However, mexiletine did not affect voltagedependent activation but negatively shifted steady-state fast and slow inactivation and markedly prolonged recovery from inactivation of $\mathrm{Na}_{\mathrm{v}} 1.5$. These actions culminated in a usedependent $I_{\mathrm{Na}}$ block in expressed $\mathrm{WT} \mathrm{Na}{ }^{+}$channels [86]. Nevertheless, mexiletine rescued negatively shifted steadystate activation voltage dependencies in SCN7A-L858F-mutated channels [20].

Recent reports have shown that ranolazine was 9 to 45 times more selective in inhibiting $I_{\mathrm{Na}-\mathrm{L}}$ than peak $I_{\mathrm{Na}}$ in isolated canine ventricular myocytes [82]. It decreased QTc interval in a group of eight LQTS3 patients carrying SCN5AD1790G. The blocking effect of ranolazine on $I_{\mathrm{Na}-\mathrm{L}}$ was recapitulated in a TSA201 expression system [16]. Meta-analysis showed that ranolazine significantly reduced incidences of AF relative to control groups in various clinical settings $[26,66]$. The trial compound GS-458967 similarly appeared to inhibit $I_{\mathrm{Na}-\mathrm{L}}$ in preference to peak $I_{\mathrm{Na}}$ particularly in the atria as opposed to the ventricles [11]. The further agent vernakalant (RSD1235) did not show selectivity for $I_{\mathrm{Na}-\mathrm{L}}$ over peak $I_{\mathrm{Na}}$ [60].

\section{Conclusions}

Sodium currents $\left(I_{\mathrm{Na}}\right)$ are strategic to cardiac excitation and are mediated by one or more $\mathrm{Na}^{+}$channel components, reflecting different states in the cardiac $\mathrm{Na}_{\mathrm{v}} 1.5$ or $\mathrm{Na}^{+}$channel species that together culminate in peak $I_{\mathrm{Na}}$ and late $I_{\mathrm{Na}-\mathrm{L}} \mathrm{com}$ ponents. Accordingly, inherited $\mathrm{Na}_{\mathrm{v}} 1.5$ abnormalities can disrupt AP generation, propagation and recovery to cause arrhythmia. In particular, an increased $I_{\mathrm{Na}-\mathrm{L}}$ leads to a variety of arrhythmic conditions and can develop from various biophysical alterations in the overall activation and inactivation gating properties of $\mathrm{Na}_{\mathrm{v}} 1.5$. Firstly, an increased overlap between the steady-state activation and inactivation functions can increase window current. Secondly, a transient kinetic failure of $\mathrm{Na}^{+}$channel inactivation can lead to bursting phenomena, characterised by frequent channel openings. Finally, a non-equilibrium gating process can cause channel reopening due to a decreased recovery time from inactivation. Available clinical evidence from different pro-arrhythmic $\mathrm{Na}_{\mathrm{v}} 1.5$ mutations can be used to illustrate each of the wide range of possible mechanisms. These various mechanisms for increasing $I_{\mathrm{Na}-\mathrm{L}}$ could provide a useful basis for the selection of therapeutic agents for patients with the disease phenotype. Selectively targeting the specific biophysical change underlying the increased $I_{\mathrm{Na}-\mathrm{L}}$ could improve efficacy and allow mutation-specific therapy. This would require preclinical 
characterisation of how the drug compounds affect the biophysical properties of the $I_{\mathrm{Na}-\mathrm{L}}$. In turn, specifically tailored drug intervention in patients with any given genetic mutation would require characterisation of their underlying electrophysiological abnormalities in order to predict their response to these drugs.

Acknowledgements $\mathrm{KC}$ was funded by the Physiological Society, United Kingdom at the University of Surrey. KJ is funded by the Fundamental Research Grant Scheme (FRGS/2/2014/SKK01/ PERDANA/02/1), Ministry of Education, Malaysia, and the Research Support Fund, Faculty of Health and Medical Science, University of Surrey. ML is funded by the British Heart Foundation (PG/14/80/ 31106, PG/16/67/32340) and Medical Research Council (G10002647). CLHH is funded by the Medical Research Council (MR/M001288/1), Wellcome Trust (105727/Z/14/Z), British Heart Foundation (PG/14/79/ 31102), the McVeigh Benefaction and SADS UK.

\section{Compliance with ethical standards}

Conflict of interest The authors declare that they have no conflict of interest.

Open Access This article is distributed under the terms of the Creative Commons Attribution 4.0 International License (http:// creativecommons.org/licenses/by/4.0/), which permits unrestricted use, distribution, and reproduction in any medium, provided you give appropriate credit to the original author(s) and the source, provide a link to the Creative Commons license, and indicate if changes were made.

\section{References}

1. Adrian RH (1978) Charge movement in the membrane of striated muscle. Annu Rev Biophys Bioeng 7:85-112. doi:10.1146/ annurev.bb.07.060178.000505

2. Alders M, Christiaans I (1993) Long QT syndrome. In: Pagon RA, Adam MP, Ardinger HH et al. (eds) GeneReviews(R). Seattle (WA)

3. Antzelevitch C (2001) Basic mechanisms of reentrant arrhythmias. Curr Opin Cardiol 16:1-7

4. Antzelevitch C, Nesterenko V, Shryock JC, Rajamani S, Song Y, Belardinelli L (2014) The role of late $I_{\mathrm{Na}}$ in development of cardiac arrhythmias. Handb Exp Pharmacol 221:137-168. doi:10.1007/ 978-3-642-41588-3 7

5. Anumonwo JM, Pandit SV (2015) Ionic mechanisms of arrhythmogenesis. Trends Cardiovasc Med 25:487-496. doi:10. 1016/j.tcm.2015.01.005

6. Arnestad M, Crotti L, Rognumi TO, Insolia R, Pedrazzini M, Ferrandi C, Vege A, Wang DW, Rhodes TE, George AL Jr, Schwartz PJ (2007) Prevalence of long-QT syndrome gene variants in sudden infant death syndrome. Circulation 115:361-367. doi:10. 1161/CIRCULATIONAHA.106.658021

7. Artigas P, Gadsby DC (2004) Large diameter of palytoxin-induced $\mathrm{Na} / \mathrm{K}$ pump channels and modulation of palytoxin interaction by $\mathrm{Na} / \mathrm{K}$ pump ligands. J Gen Physiol 123:357-376. doi:10.1085/jgp. 200308964

8. Balser JR (1999) Structure and function of the cardiac sodium channels. Cardiovasc Res 42:327-338

9. Behr E, Wood DA, Wright M, Syrris P, Sheppard MN, Casey A, Davies MJ, McKenna W, Sudden Arrhythmic Death Syndrome
Steering G (2003) Cardiological assessment of first-degree relatives in sudden arrhythmic death syndrome. Lancet 362:1457-1459

10. Bezzina CR, Lahrouchi N, Priori SG (2015) Genetics of sudden cardiac death. Circ Res 116:1919-1936. doi:10.1161/ CIRCRESAHA.116.304030

11. Burashnikov A, Di Diego JM, Goodrow RJ Jr, Belardinelli L, Antzelevitch C (2015) Atria are more sensitive than ventricles to GS-458967-induced inhibition of late sodium current. J Cardiovasc Pharmacol Ther 20:501-508. doi:10.1177/1074248415570636

12. Cannon SC, Brown RH Jr, Corey DP (1993) Theoretical reconstruction of myotonia and paralysis caused by incomplete inactivation of sodium channels. Biophys J 65:270-288. doi:10.1016/ S0006-3495(93)81045-2

13. Catterall WA (2012) Voltage-gated sodium channels at 60: structure, function and pathophysiology. J Physiol 590:2577-2589. doi: 10.1113/jphysiol.2011.224204

14. Chandler WK, Meves H (1970) Sodium and potassium currents in squid axons perfused with fluoride solutions. J Physiol 211:623652

15. Cheng H, Li J, James AF, Inada S, Choisy SC, Orchard CH, Zhang H, Boyett MR, Hancox JC (2016) Characterization and influence of cardiac background sodium current in the atrioventricular node. J Mol Cell Cardiol 97:114-124. doi:10.1016/j.yjmcc.2016.04.014

16. Chorin E, Hu D, Antzelevitch C, Hochstadt A, Belardinelli L, Zeltser D, Barajas-Martinez H, Rozovski U, Rosso R, Adler A, Benhorin J, Viskin S (2016) Ranolazine for congenital long-QT syndrome type III: experimental and long-term clinical data. Circ Arrhythm Electrophysiol 9. doi:10.1161/CIRCEP.116.004370

17. Chugh SS, Reinier K, Teodorescu C, Evanado A, Kehr E, Al Samara M, Mariani R, Gunson K, Jui J (2008) Epidemiology of sudden cardiac death: clinical and research implications. Prog Cardiovasc Dis 51:213-228. doi:10.1016/j.pcad.2008.06.003

18. Clancy CE, Rudy Y (1999) Linking a genetic defect to its cellular phenotype in a cardiac arrhythmia. Nature 400:566-569. doi:10. $1038 / 23034$

19. Clancy CE, Tateyama M, Liu H, Wehrens XH, Kass RS (2003) Non-equilibrium gating in cardiac $\mathrm{Na}^{+}$channels: an original mechanism of arrhythmia. Circulation 107:2233-2237. doi:10.1161/01. CIR.0000069273.51375.BD

20. Cregg R, Cox JJ, Bennett DL, Wood JN, Werdehausen R (2014) Mexiletine as a treatment for primary erythromelalgia: normalization of biophysical properties of mutant L858F NaV 1.7 sodium channels. Br J Pharmacol 171:4455-4463. doi:10.1111/bph.12788

21. Detta N, Frisso G, Salvatore F (2015) The multi-faceted aspects of the complex cardiac Nav1.5 protein in membrane function and pathophysiology. Biochim Biophys Acta 1854:1502-1509. doi: 10.1016/j.bbapap.2015.07.009

22. Featherstone DE, Fujimoto E, Ruben PC (1998) A defect in skeletal muscle sodium channel deactivation exacerbates hyperexcitability in human paramyotonia congenita. J Physiol 506(Pt 3):627-638

23. Gaztanaga L, Marchlinski FE, Betensky BP (2012) Mechanisms of cardiac arrhythmias. Rev Esp Cardiol (Engl Ed) 65:174-185. doi: 10.1016/j.recesp.2011.09.018

24. Gilchrist J, Dutton S, Diaz-Bustamante M, McPherson A, Olivares N, Kalia J, Escayg A, Bosmans F (2014) Nav1.1 modulation by a novel triazole compound attenuates epileptic seizures in rodents. ACS Chem Biol 9:1204-1212. doi:10.1021/cb500108p

25. Gintant GA, Datyner NB, Cohen IS (1984) Slow inactivation of a tetrodotoxin-sensitive current in canine cardiac Purkinje fibers. Biophys J 45:509-512. doi:10.1016/S0006-3495(84)84187-9

26. Gong M, Zhang Z, Fragakis N, Korantzopoulos P, Letsas KP, Li G, Yan GX, Liu T (2016) The role of ranolazine in the prevention and treatment of atrial fibrillation: a meta-analysis of randomized clinical trials. Heart Rhythm. doi:10.1016/j.hrthm.2016.10.008

27. Hakim P, Gurung IS, Pedersen TH, Thresher R, Brice N, Lawrence J, Grace AA, Huang CL (2008) Scn3b knockout mice exhibit 
abnormal ventricular electrophysiological properties. Prog Biophys Mol Biol 98:251-266. doi:10.1016/j.pbiomolbio.2009.01.005

28. Hayward LJ, Brown RH Jr, Cannon SC (1996) Inactivation defects caused by myotonia-associated mutations in the sodium channel III-IV linker. J Gen Physiol 107:559-576

29. Hayward LJ, Brown RH Jr, Cannon SC (1997) Slow inactivation differs among mutant $\mathrm{Na}$ channels associated with myotonia and periodic paralysis. Biophys J 72:1204-1219. doi:10.1016/S00063495(97)78768-X

30. Head CE, Balasubramaniam R, Thomas G, Goddard CA, Lei M, Colledge WH, Grace AA, Huang CL (2005) Paced electrogram fractionation analysis of arrhythmogenic tendency in DeltaKPQ Scn5a mice. J Cardiovasc Electrophysiol 16:1329-1340. doi:10. 1111/j.1540-8167.2005.00200.x

31. Hilgemann DW (2004) New insights into the molecular and cellular workings of the cardiac $\mathrm{Na}^{+} / \mathrm{Ca}^{2+}$ exchanger. Am J Physiol Cell Physiol 287:C1167-C1172. doi:10.1152/ajpcell.00288.2004

32. Hodgkin AL, Huxley AF (1952) A quantitative description of membrane current and its application to conduction and excitation in nerve. J Physiol 117:500-544.

33. Horne AJ, Eldstrom J, Sanatani S, Fedida D (2011) A novel mechanism for LQT3 with 2:1 block: a pore-lining mutation in Nav1.5 significantly affects voltage-dependence of activation. Heart Rhythm 8:770-777. doi:10.1016/j.hrthm.2010.12.041

34. Huang H, Millat G, Rodriguez-Lafrasse C, Rousson R, Kugener B, Chevalier P, Chahine M (2009) Biophysical characterization of a new SCN5A mutation S1333Y in a SIDS infant linked to long QT syndrome. FEBS Lett 583:890-896. doi:10.1016/j.febslet.2009.02. 007

35. Jabbari J, Olesen MS, Yuan L, Nielsen JB, Liang B, Macri V, Christophersen IE, Nielsen N, Sajadieh A, Ellinor PT, Grunnet M, Haunso S, Holst AG, Svendsen JH, Jespersen T (2015) Common and rare variants in SCN10A modulate the risk of atrial fibrillation. Circ Cardiovasc Genet 8:64-73. doi:10.1161/HCG. 0000000000000022

36. January CT, Riddle JM (1989) Early afterdepolarizations: mechanism of induction and block. A role for L-type $\mathrm{Ca}^{2+}$ current. Circ Res 64:977-990

37. Ju YK, Saint DA, Gage PW (1992) Effects of lignocaine and quinidine on the persistent sodium current in rat ventricular myocytes. Br J Pharmacol 107:311-316

38. Kass RS (2004) Sodium channel inactivation goes with the flow. J Gen Physiol 124:7-8. doi:10.1085/jgp.200409123

39. King JH, Huang CLH, Fraser JA (2013) Determinants of myocardial conduction velocity: implications for arrhythmogenesis. Front Physiol 4:154. doi:10.3389/fphys.2013.00154

40. Klaver EC, Versluijs GM, Wilders R (2011) Cardiac ion channel mutations in the sudden infant death syndrome. Int J Cardiol 152: 162-170. doi:10.1016/j.ijcard.2010.12.051

41. Ko D, Rahman F, Schnabel RB, Yin X, Benjamin EJ, Christophersen IE (2016) Atrial fibrillation in women: epidemiology, pathophysiology, presentation, and prognosis. Nat Rev Cardiol 13:321-332. doi:10.1038/nrcardio.2016.45

42. Kyndt F, Probst V, Potet F, Demolombe S, Chevallier JC, Baro I, Moisan JP, Boisseau P, Schott JJ, Escande D, Le Marec H (2001) Novel SCN5A mutation leading either to isolated cardiac conduction defect or Brugada syndrome in a large French family. Circulation 104:3081-3086. doi:10.1161/hc5001.100834

43. Laurent G, Saal S, Amarouch MY, Beziau DM, Marsman RF, Faivre L, Barc J, Dina C, Bertaux G, Barthez O, Thauvin-Robinet C, Charron P, Fressart V, Maltret A, Villain E, Baron E, Merot J, Turpault R, Coudiere Y, Charpentier F, Schott JJ, Loussouarn G, Wilde AA, Wolf JE, Baro I, Kyndt F, Probst V (2012) Multifocal ectopic Purkinje-related premature contractions: a new SCN5Arelated cardiac channelopathy. J Am Coll Cardiol 60:144-156. doi:10.1016/j.jacc.2012.02.052
44. Lehmann-Horn F, Jurkat-Rott K (1999) Voltage-gated ion channels and hereditary disease. Physiol Rev 79:1317-1372

45. Lehmann-Horn F, Rudel R, Ricker K (1987) Membrane defects in paramyotonia congenita (Eulenburg). Muscle Nerve 10:633-641. doi:10.1002/mus.880100709

46. Li Q, Huang H, Liu G, Lam K, Rutberg J, Green MS, Birnie DH, Lemery R, Chahine M, Gollob MH (2009) Gain-of-function mutation of Nav1.5 in atrial fibrillation enhances cellular excitability and lowers the threshold for action potential firing. Biochem Biophys Res Commun 380:132-137. doi:10.1016/j.bbrc.2009.01.052

47. Loussouarn G, Sternberg D, Nicole S, Marionneau C, Le Bouffant F, Toumaniantz G, Barc J, Malak OA, Fressart V, Pereon Y, Baro I, Charpentier F (2015) Physiological and pathophysiological insights of Nav1.4 and Nav1.5 comparison. Front Pharmacol 6:314. doi:10. 3389/fphar.2015.00314

48. Makielski JC (2016) Late sodium current: a mechanism for angina, heart failure, and arrhythmia. Trends Cardiovase Med 26:115-122. doi:10.1016/j.tcm.2015.05.006

49. Malan D, Zhang M, Stallmeyer B, Muller J, Fleischmann BK, Schulze-Bahr E, Sasse P, Greber B (2016) Human iPS cell model of type 3 long QT syndrome recapitulates drug-based phenotype correction. Basic Res Cardiol 111:14. doi:10.1007/s00395-0160530-0

50. Mantegazza M, Catterall WA (2012) Voltage-gated $\mathrm{Na}^{+}$channels: structure, function, and pathophysiology. In: Noebels JL, Avoli M, Rogawski MA, Olsen RW, Delgado-Escueta AV (eds) Jasper's Basic Mechanisms of the Epilepsies. 4th edn., Bethesda (MD)

51. Martin CA, Siedlecka U, Kemmerich K, Lawrence J, Cartledge J, Guzadhur L, Brice N, Grace AA, Schwiening C, Terracciano CM, Huang CL (2012) Reduced $\mathrm{Na}(+)$ and higher $\mathrm{K}(+)$ channel expression and function contribute to right ventricular origin of arrhythmias in Scn5a $\mathrm{a}^{+-}$mice. Open Biol 2:120072. doi:10.1098/rsob. 120072

52. Mehta AR, Huang CL, Skepper JN, Fraser JA (2008) Extracellular charge adsorption influences intracellular electrochemical homeostasis in amphibian skeletal muscle. Biophys J 94:4549-4560. doi: 10.1529/biophysj.107.128587

53. Moreau A, Gosselin-Badaroudine P, Boutjdir M, Chahine M (2015) Mutations in the voltage sensors of domains I and II of Nav1.5 that are associated with arrhythmias and dilated cardiomyopathy generate gating pore currents. Front Pharmacol 6:301. doi:10.3389/fphar. 2015.00301

54. Moreno JD, Clancy CE (2012) Pathophysiology of the cardiac late $\mathrm{Na}$ current and its potential as a drug target. J Mol Cell Cardiol 52: 608-619. doi:10.1016/j.yjmcc.2011.12.003

55. Musa H, Kline CF, Sturm AC, Murphy N, Adelman S, Wang C, Yan H, Johnson BL, Csepe TA, Kilic A, Higgins RS, Janssen PM, Fedorov VV, Weiss R, Salazar C, Hund TJ, Pitt GS, Mohler PJ (2015) SCN5A variant that blocks fibroblast growth factor homologous factor regulation causes human arrhythmia. Proc Natl Acad Sci U S A 112:12528-12533. doi:10.1073/pnas.1516430112

56. Nakatani Y, Masuko H, Amano T (2013) Effect of lamotrigine on $\mathrm{Na}(\mathrm{v}) 1.4$ voltage-gated sodium channels. J Pharmacol Sci 123: 203-206

57. Nerbonne JM, Kass RS (2005) Molecular physiology of cardiac repolarization. Physiol Rev 85:1205-1253. doi:10.1152/physrev. 00002.2005

58. Noble D, Noble PJ (2006) Late sodium current in the pathophysiology of cardiovascular disease: consequences of sodium-calcium overload. Heart 92(Suppl 4):iv1-iv5. doi:10.1136/hrt.2005.078782

59. Nolasco JB, Dahlen RW (1968) A graphic method for the study of alternation in cardiac action potentials. J Appl Physiol 25:191-196

60. Orth PM, Hesketh JC, Mak CK, Yang Y, Lin S, Beatch GN, Ezrin AM, Fedida D (2006) RSD1235 blocks late $I_{\mathrm{Na}}$ and suppresses early afterdepolarizations and torsades de pointes induced by class 
III agents. Cardiovasc Res 70:486-496. doi:10.1016/j.cardiores. 2006.01.026

61. Ortiz-Bonnin B, Rinne S, Moss R, Streit AK, Scharf M, Richter K, Stober A, Pfeufer A, Seemann G, Kaab S, Beckmann BM, Decher N (2016) Electrophysiological characterization of a large set of novel variants in the SCN5A-gene: identification of novel LQTS3 and BrS mutations. Pflugers Arch. doi:10.1007/s00424-016-1844-3

62. Payandeh J, Scheuer T, Zheng N, Catterall WA (2011) The crystal structure of a voltage-gated sodium channel. Nature 475:353-358. doi:10.1038/nature10238

63. Rakowski RF, Gadsby DC, De Weer P (2002) Single ion occupancy and steady-state gating of $\mathrm{Na}$ channels in squid giant axon. $\mathrm{J}$ Gen Physiol 119:235-249

64. Remme CA, Bezzina CR (2010) Sodium channel (dys)function and cardiac arrhythmias. Cardiovasc Ther 28:287-294. doi:10.1111/j. 1755-5922.2010.00210.x

65. Ruan Y, Liu N, Bloise R, Napolitano C, Priori SG (2007) Gating properties of SCN5A mutations and the response to mexiletine in long-QT syndrome type 3 patients. Circulation 116:1137-1144. doi:10.1161/CIRCULATIONAHA.107.707877

66. Saad M, Mahmoud A, Elgendy IY, Richard Conti C (2016) Ranolazine in cardiac arrhythmia. Clin Cardiol 39:170-178. doi: $10.1002 /$ clc. 22476

67. Saint DA (2008) The cardiac persistent sodium current: an appealing therapeutic target? Br J Pharmacol 153:1133-1142. doi:10. 1038/sj.bjp.0707492

68. Saint DA, Ju YK, Gage PW (1992) A persistent sodium current in rat ventricular myocytes. J Physiol 453:219-231

69. Sallansonnet-Froment M, Bounolleau P, De Greslan T, Ricard D, Taillia H, Renard JL (2007) Eulenburg's paramyotonia congenita. Rev Neurol (Paris) 163:1083-1090

70. Schmitt N, Grunnet M, Olesen SP (2014) Cardiac potassium channel subtypes: new roles in repolarization and arrhythmia. Physiol Rev 94:609-653. doi:10.1152/physrev.00022.2013

71. Schram G, Pourrier M, Melnyk P, Nattel S (2002) Differential distribution of cardiac ion channel expression as a basis for regional specialization in electrical function. Circ Res 90:939-950

72. Shinlapawittayatorn K, Du XX, Liu H, Ficker E, Kaufman ES, Deschenes I (2011) A common SCN5A polymorphism modulates the biophysical defects of SCN5A mutations. Heart Rhythm 8:455462. doi:10.1016/j.hrthm.2010.11.034

73. Skov M, De Paoli FV, Lausten J, Nielsen OB, Pedersen TH (2015) Extracellular magnesium and calcium reduce myotonia in isolated ClC-1 chloride channel-inhibited human muscle. Muscle Nerve 51: 65-71. doi:10.1002/mus. 24260

74. Skov M, de Paoli FV, Nielsen OB, Pedersen TH (2016) The anticonvulsants lacosamide, lamotrigine and rufinamide reduce myotonia in isolated human and rat skeletal muscle. Muscle Nerve. doi: $10.1002 /$ mus. 25452
75. Skov M, Riisager A, Fraser JA, Nielsen OB, Pedersen TH (2013) Extracellular magnesium and calcium reduce myotonia in $\mathrm{ClC}-1$ inhibited rat muscle. Neuromuscul Disord 23:489-502. doi:10. 1016/j.nmd.2013.03.009

76. Song Y, Shryock JC, Belardinelli L (2009) A slowly inactivating sodium current contributes to spontaneous diastolic depolarization of atrial myocytes. Am J Physiol Heart Circ Physiol 297:H1254 H1262. doi:10.1152/ajpheart.00444.2009

77. Swan H, Amarouch MY, Leinonen J, Marjamaa A, Kucera JP, Laitinen-Forsblom PJ, Lahtinen AM, Palotie A, Kontula K, Toivonen L, Abriel H, Widen E (2014) Gain-of-function mutation of the SCN5A gene causes exercise-induced polymorphic ventricular arrhythmias. Circ Cardiovasc Genet 7:771-781. doi:10.1161/ CIRCGENETICS.114.000703

78. Taggart P, Lab M (2008) Cardiac mechano-electric feedback and electrical restitution in humans. Prog Biophys Mol Biol 97:452460. doi:10.1016/j.pbiomolbio.2008.02.021

79. Tateyama M, Rivolta I, Clancy CE, Kass RS (2003) Modulation of cardiac sodium channel gating by protein kinase $\mathrm{A}$ can be altered by disease-linked mutation. J Biol Chem 278:46718-46726. doi:10. 1074/jbc.M308977200

80. Tester DJ, Ackerman MJ (2007) Postmortem long QT syndrome genetic testing for sudden unexplained death in the young. J Am Coll Cardiol 49:240-246. doi:10.1016/j.jacc. 2006.10.010

81. Ulbricht W (2005) Sodium channel inactivation: molecular determinants and modulation. Physiol Rev 85:1271-1301. doi:10.1152/ physrev.00024.2004

82. Undrovinas AI, Belardinelli L, Undrovinas NA, Sabbah HN (2006) Ranolazine improves abnormal repolarization and contraction in left ventricular myocytes of dogs with heart failure by inhibiting late sodium current. J Cardiovasc Electrophysiol 17(Suppl 1): S169-S177. doi:10.1111/j.1540-8167.2006.00401.x

83. Vassilev P, Scheuer T, Catterall WA (1989) Inhibition of inactivation of single sodium channels by a site-directed antibody. Proc Natl Acad Sci U S A 86:8147-8151

84. Verkerk AO, Remme CA, Schumacher CA, Scicluna BP, Wolswinkel R, de Jonge B, Bezzina CR, Veldkamp MW (2012) Functional Nav1.8 channels in intracardiac neurons: the link between SCN10A and cardiac electrophysiology. Circ Res 111:333343. doi:10.1161/CIRCRESAHA.112.274035

85. Wang T, Wehrens XH (2012) Enhanced impact of SCN5A mutation associated with long QT syndrome in fetal splice isoform. Heart Rhythm 9:598-599. doi:10.1016/j.hrthm.2011.11.049

86. Wang Y, Mi J, Lu K, Lu Y, Wang K (2015) Comparison of gating properties and use-dependent block of Nav1.5 and Nav1.7 channels by anti-arrhythmics mexiletine and lidocaine. PLoS One 10: e0128653. doi:10.1371/journal.pone. 0128653

87. Zipes DP (2003) Mechanisms of clinical arrhythmias. J Cardiovasc Electrophysiol 14:902-912 